\title{
QUALITY CHANGES OF FRESH DUMPLING WRAPPERS AT ROOM TEMPERATURE
}

\author{
- Research paper - \\ Yunfeng $\mathrm{HU}^{1}$, Zengyu WEI, Yuanyuan CHEN \\ College of Food Engineering and Biotechnology, Tianjin University of Science and Technology, \\ Tianjin 300457, China
}

\begin{abstract}
In this paper, the quality changes of fresh dumpling wrappers during storage were studied by measuring the changes of microbial growth, color, $\mathrm{pH}$, texture, cooking property, moisture content and distribution of raw dumpling wrappers. The correlation of these indicators was analyzed. The results showed that the dumpling wrappers had generated lots of microorganisms during storage and the $\mathrm{pH}$ value decreased gradually. The dumpling wrappers had browning and the color became darker. The texture of the dumpling wrappers changed obviously. The original structure of raw dumpling wrappers were destroyed, the water distribution is uneven and migration to the surface. The apparent index of raw dumpling wrappers has a significant correlation with the internal change, which provides a certain guiding significance for maintaining the good quality of dumpling wrappers.
\end{abstract}

Key words: dumpling wrappers, NMR, microorganisms, quality change

\section{INTRODUCTION}

'Dumpling', which originated in the era of Zhong-jing Zhang, the China's medical St, can be described as a long history. It is also known as 'jiao zi' or 'jiao er'. Dumplings have already become the unique diet of Chinese people, and Chinese people often eat them at the Spring Festival.

Wheat flour is the main component of dumpling wrappers (Lan et al., 2010). Ying-guo Lu (Lu et al., 2013) showed that wheat hardness and sedimentation value significantly affected the texture quality of frozen dumpling wrappers, and the gluten index and gluten content have an indirect effect on the quality of frozen dumplings. Lan-bo and others studies (Lan et al., 2010) have shown that dough strength index dumpling wrappers elasticity and hardness score have a negative effect on the appearance of dumpling wrappers from the positive effect. The starch content with high proportion can reduce the surface hardness and viscosity of the dumpling. The less content of the amylose, the better surface elasticity of the dumpling will be. The protein and starch are the main factors which determine the quality of food processing (Sun et al., 2009). It is generally believed that the gluten protein determines the baking quality of wheat flour, and the quality of noodles and dumpling wrappers are affected by the quality of starch besides the influence of protein (Wrigley et al., 1997; Baik et al., 1994). Gluten protein is mainly composed of glutenin and alcohol soluble protein, determine the dough elasticity and ductility and other rheological properties (Huang et al., 1998; Addo et al., 1991). Gliadin and glutenin in dough combine according to a certain rule, and form a network like a sponge which makes up the gluten skeleton. And other ingredients such as fat, sugar, starch and water are contained in the skeleton, which makes the gluten with elasticity and plasticity (Yu et al., 2010). Gluten proteins confer dough rheological

${ }^{1}$ Corresponding author. Mailing address: hu-yf@163.com 
properties such as water retention, dough adhesion and viscoelastic properties ( $\mathrm{Li}$ et al., 2003).

The mechanism of the increase in hardness during dough formation is not well understood but is generally believed to be the result of optimization of the protein interaction in the dough. At the molecular level, this optimization comes from the disulfide bond exchange (Zhang, 2013). In the process of dumpling wrappers production, some free sulfhydryl groups combine to form disulfide bonds, thus promoting the formation of gluten network structure. Therefore, the free sulfhydryl content in dumpling wrappers can be used as an important index to characterize the degree of gluten network structure formation (Gujral and Rosell, 2004).

Li et al. (2012) had studied on the relationship between sensory quality and texture quality of quick-frozen dumpling wrappers. The results showed that the texture and quality of fresh dumpling wrappers could be reflected by texture testing indexes such as Cohesiveness, Cumminess and Chewiness. (Liu et al., 2012) and other studies have shown that: moisture content of the mechanical properties of

\section{MATERIALS AND METHODS}

Materials: wheat flour was obtained from Lijin Foodstuff and Edible Oil corporation ltd (Tianjin, China). All chemical reagents were of analytical grade. The moisture content was measured with a Moisture analyzer (XQ501, Shanghai, China). The $\mathrm{pH}$ value was measured with a $\mathrm{pH}$ meter (MP522, Shanghai, China).

Analysis of ingredients and silty characteristics of dumplings flour: determination of moisture content according to GB 5009.3-2010(GB 5009.3-2010, 2010). The ash content was determined according to GB 5009.4-2010(GB 5009.4-2010, 2010). Determination of protein content was according to GB 5009.5-2010 (GB 5009.4-2010, 2010). Determination of starch content was according to GB 5009.9-1985 (GB 5009.9-1985, 1985). Determination of gluten in wheat flour was according to GB/T 5506.1-2008 (GB/T 5506.1-2008, 2008). Determination of physical characteristics of doughs was according dumpling dough has a significant impact. Nuclear magnetic resonance (Pitombo et al., 2003; Mcentryr et al., 1998; Clark et al., 1998) is a new technology applied in food field. It can study the distribution and migration of moisture in food microscopically. It is fast, non-destructive and accurate. Tian-tian Li's (Li et al., 2014) study showed that there were significant correlations among moisture content, transverse relaxation time $\mathrm{T} 2$, acidity, texture, color and other indexes in fresh wet noodles under different storage conditions. Since the composition and structure of fresh dumpling wrappers are similar to those of wet noodles, and there are few literatures on the quality change of dumpling wrappers during storage, this paper explores the effects of dumpling wrappers by NMR to explore the content of different status water and its convective change in fresh dumplings during storage. The correlation between the results and the texture index and quality index of fresh dumpling wrappers was analyzed, and their internal relationship was preliminarily discussed, which provided certain guiding significance for maintaining good quality of dumpling wrapper.

to GB/T 14614-2006 (GB/T 14614-2006, 2006). Fresh dumplings wrappers preparation: under the conditions of analog industrial production, the lab, including all instruments and packing materials, was sterilized using ultraviolet radiation. The production of dumplings wrappers was carried out using the method described by (Li et al., 2012).

Experimental processing method: the pressed surface was cut on a noodle machine (SM-168S Murenking, Shenzhen, China), cut into $2.0 \mathrm{~mm}$ wide dumplings wrappers and the wet dumplings wrappers were cut into $22 \mathrm{~cm}$ long specimens. Then put the dumplings wrappers in the PE bag, $500 \mathrm{~g}$ per bag, stored at $25^{\circ} \mathrm{C}$ for 6 days. The total colony count, brightness $\mathrm{L}^{*}$ value, redness a value, $\mathrm{pH}$ value, texture property and nuclear magnetic resonance relaxation were measured every day, according to Standards Association of China. Five sets of 
parallel experiments were set up, and the data were analyzed by averaging.

Determination of water distribution in fresh dumpling wrappers: the water distribution and migration of fresh dumpling wrappers was observed with an NMR system (MicroMR-025, Niumag Electronics Technology Co., Ltd.), at 0 d, $1 \mathrm{~d}, 2 \mathrm{~d}, 3 \mathrm{~d}, 4 \mathrm{~d}, 5 \mathrm{~d}$ and $6 \mathrm{~d}$, respectively. The samples were accurately weighed and then were placed in the test tube, sealed with sealing film to prevent moisture volatilization. The transverse relaxation time was measured by low frequency nuclear magnetic resonance (NMR). The test temperature was $32{ }^{\circ} \mathrm{C}$. The parameters are as follows: the number of sampling points TD is 19994, the number of echo NECH is 1000 , the repeated scan times NS is 4 , and the time interval of repeated sampling is $1000 \mathrm{~ms}$. The analysis software and CPMG sequence were used to collect dough T2 signals, and each sample was repeated 3 times. The obtained graph is an exponential decay pattern, and the distribution of relaxation time is obtained by entering the $\mathrm{T} 2$ inversion program.

Free sulfhydryl (-SH) determination: the Free sulfhydryl (-SH) determination were used as described by (Wang et al., 2006)

Determination of microbial indicators: the total number of colonies in accordance with GB/T 4789.2-2010. The total number of molds was accordance with GB/T 4789.15-2010.

Color analysis: The surface color of dumpling wrappers was measured with a CR-10 Colorimeter (Ke Shengxing Instrument Co, Ltd, China). The values of ' $\mathrm{L}^{*}$ ' (light/dark) and ' $\mathrm{a}$ ' (red/green) were measured separately (Li et al., 2008).

$\mathrm{pH}$ analysis: weigh $10 \mathrm{~g}$ dumpling wrappers, add

\section{RESULTS AND DICUSSIONS}

\section{Composition and silty characteristics analysis of the dumplings flour}

The determination results of the basic composition and silty characteristics of the raw flour are shown in Table 1 and table 2 . According to the current standard LS/T 3203-1993(LS/T 3203-1993, 1993), the main indexes and limits are: moisture content $\leq 14.5 \%$,
$90 \mathrm{ml}$ of deionized water ground into a homogenate, with a pH meter(MP522, Shanghai, China) to determine the $\mathrm{pH}$ value.

Determination of cortical parameters of fresh dumpling: the hardness, adhesiveness, springiness, and chewiness of cooked dumpling wrappers were periodically determined using a Texture Analyzer (TA. XT. Plus, London, England). In the test, three parallel dough samples were taken under the probe, and compressed by TPA mode and P/36 R cylindrical probe. The measurement parameters are as follows: Pre test speed: $2 \mathrm{~mm} / \mathrm{s}$; test speed: $0.8 \mathrm{~mm} / \mathrm{s}$; post test speed: $0.8 \mathrm{~mm} / \mathrm{s}$; triggering force: $5 \mathrm{~g}$; compression rate: $75 \%$. The results of the three measurements were recorded and the average was taken as the final result ( $\mathrm{Li}$ et al., 2008).

Determination of cooking characteristics of raw dumpling wrappers: The determination of optimum cooking time for dumpling wrappers, determination of water absorption of dumpling wrappers dry matter, determination of dumpling wrappers cooking loss rate were used as described by Zhang (Zhang et al., 2005).

Data processing: All experimental data were presented as the mean of at least three readings. Significant differences were verified by one-way analysis using SPSS statistical software (17.0, SPSS Inc., Chicago, IL, USA). P $<0.05$ was considered statistically significant with Duncan's test. Pearson correlation (r) and factor analysis (FA) were also performed (using SPSS) to determine the relationship between different variables and screen out the principal parameters to indicate fresh dumpling wrappers deterioration.

ash content $\leq 0.55 \%$, wet gluten content $28 \%$ $32 \%$, dough stability time $\geq 3.5 \mathrm{~min}$. The test results indicate that the four raw flour indexes such as ash content, wet gluten content and dough stability time are in line with the standard requirements. Thus, the raw wheat flour is suitable for making dumpling wrappers. 
Table 1 .Basic composition of Wheat flour

\begin{tabular}{|l|l|l|l|l|l|}
\hline index & Moisture (\%) & Ash (\%) & Protein (\%) & Wet gluten (\%) & Starch content (\%) \\
\hline $\begin{array}{l}\text { Measurement } \\
\text { results }\end{array}$ & $11.68 \pm 0.03$ & $0.48 \pm 0.02$ & $9.43 \pm 0.3$ & $30.9 \pm 1.9$ & $57.69 \pm 0.5$ \\
\hline
\end{tabular}

Table 2 .Silty characteristics of wheat flour

\begin{tabular}{|l|l|l|l|l|l|}
\hline index & $\begin{array}{l}\text { Absorption } \\
\text { ratio (\%) }\end{array}$ & $\begin{array}{l}\text { Development } \\
\text { time(min) }\end{array}$ & $\begin{array}{l}\text { Stability } \\
\text { time(min) }\end{array}$ & $\begin{array}{l}\text { Degree of softening } \\
\text { (FU) }\end{array}$ & $\begin{array}{l}\text { Silty quality } \\
\text { index }\end{array}$ \\
\hline $\begin{array}{l}\text { Measurement } \\
\text { results }\end{array}$ & $62.81 \pm 0.35$ & $3.91 \pm 0.05$ & $6.23 \pm 0.17$ & $89.25 \pm 1.33$ & $58.93 \pm 0.64$ \\
\hline
\end{tabular}

Changes in moisture content of dumpling wrappers during storage at room temperature

Moisture content is an important indicator of the quality of dumpling wrappers. Suitable moisture content can make dumpling surface more smooth and delicate. Otherwise, the quality of color and taste of dumpling wrappers will decrease (Wang et al., 2013). From Figure 1, the moisture content of the dumpling wrappers decreased with the prolonging of storage time. In the first 4 days of the storage period, the decreasing trend of water content was more obvious, and it began to balance from the fifth days. The reason may be that the dumpling wrapper's water is mainly composed of bound water, weak binding water and free water, in which free water is more likely to evaporate, and weakly bound water and bound water are more difficult to evaporate and dissipate. The free water with low content at the beginning of storage begins to evaporate first, the moisture content of the dumpling wrappers decreased gradually. The weak binding water began to evaporate, but the evaporation trend was relatively slow. At this time, the moisture content began to slow down.

\section{Change of moisture distribution in dumpling wrappers during storage at room temperature}

Figure 2.presents the $\mathrm{T} 2$ inversion diagram of the transverse relaxation time of dumpling wrappers. The two peaks T22 and T23 represent the two kinds of moisture in the dumpling wrappers, and T22 in the range of $0.49 \sim 21.54$ $\mathrm{ms}$ is weak combined with water, this part of the water in the protein, starch and other macromolecules, poor mobility, not easy to lose. And in the $32.75 \sim 151.99 \mathrm{~ms}$ range of T23 is free water, good mobility, easy to lose (Liu et al., 2015). The transverse relaxation time and the relative percentages of moisture in the dumpling wrappers during storage are shown in Table 3.

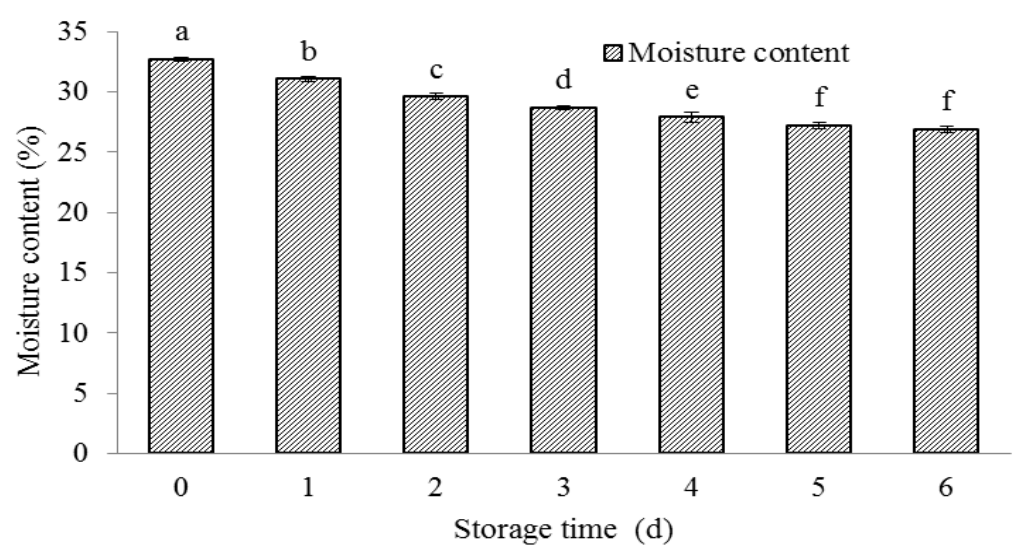

Figure 1 .Changes of moisture content of dumpling wrappers during storage 


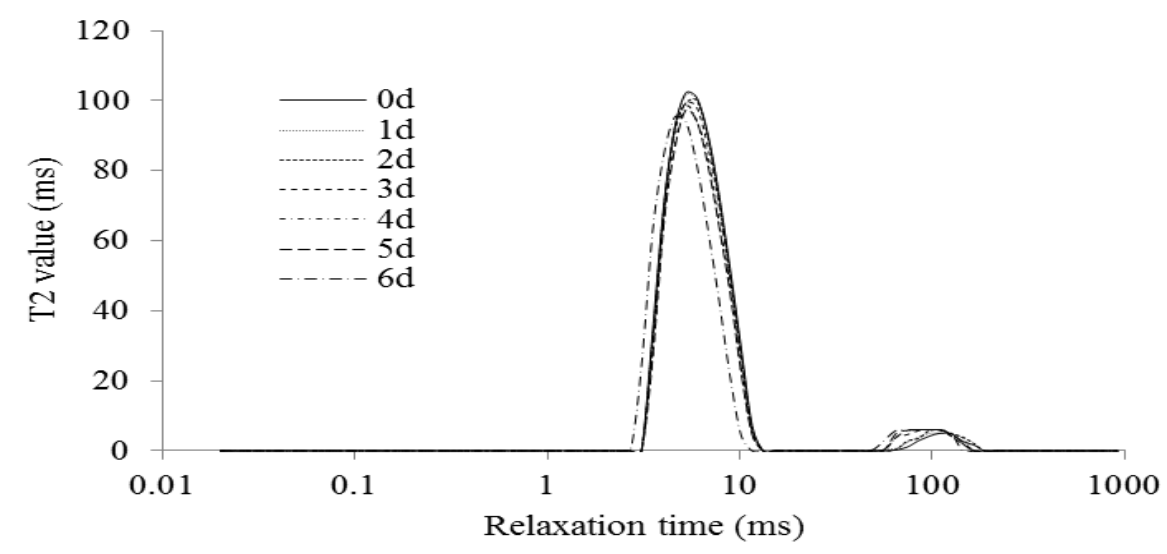

Figure 2.Water inversion results of transverse relation times $\mathrm{T} 2$ in dumpling wrappers during storage

Table3. The change of transverse relaxation time $\mathrm{T} 2$ and proportion of dumpling wrappers during storage

\begin{tabular}{|l|l|l|l|l|}
\hline $\begin{array}{l}\text { Storage } \\
\text { time }(\mathrm{d})\end{array}$ & $\begin{array}{l}\text { Weakly bound water } \\
\text { transverse relaxation } \\
\text { time } \mathrm{T}_{22}(\mathrm{~ms})\end{array}$ & $\begin{array}{l}\text { Free water transverse } \\
\text { relaxation time } \mathrm{T}_{23} \\
(\mathrm{~ms})\end{array}$ & $\begin{array}{l}\text { Weakly bound water } \\
\text { peak area percentage } \\
\mathrm{P}_{22}(\%)\end{array}$ & $\begin{array}{l}\text { Free water peak } \\
\text { area percentage } \\
\mathrm{P}_{23}(\%)\end{array}$ \\
\hline 0 & $5.97 \pm 0.00^{\mathrm{a}}$ & $110.35 \pm 0.00^{\mathrm{a}}$ & $96.61 \pm 0.01^{\mathrm{a}}$ & $3.39 \pm 0.01^{\mathrm{a}}$ \\
\hline 1 & $5.97 \pm 0.10^{\mathrm{a}}$ & $110.35 \pm 0.00^{\mathrm{a}}$ & $96.09 \pm 0.02^{\mathrm{b}}$ & $3.91 \pm 0.02^{\mathrm{b}}$ \\
\hline 2 & $5.97 \pm 0.00^{\mathrm{a}}$ & $110.35 \pm 0.20^{\mathrm{a}}$ & $95.56 \pm 0.01^{\mathrm{c}}$ & $4.44 \pm 0.01^{\mathrm{c}}$ \\
\hline 3 & $5.23 \pm 0.00^{\mathrm{b}}$ & $96.65 \pm 0.00^{\mathrm{b}}$ & $95.00 \pm 0.01^{\mathrm{d}}$ & $5.00 \pm 0.01^{\mathrm{d}}$ \\
\hline 4 & $5.23 \pm 0.10^{\mathrm{b}}$ & $96.65 \pm 0.10^{\mathrm{b}}$ & $94.53 \pm 0.03^{\mathrm{e}}$ & $5.47 \pm 0.03^{\mathrm{e}}$ \\
\hline 5 & $5.23 \pm 0.20^{\mathrm{b}}$ & $96.65 \pm 0.00^{\mathrm{b}}$ & $94.07 \pm 0.02^{\mathrm{f}}$ & $5.93 \pm 0.02^{\mathrm{f}}$ \\
\hline 6 & $4.58 \pm 0.00^{\mathrm{c}}$ & $84.65 \pm 0.00^{\mathrm{c}}$ & $93.65 \pm 0.04^{\mathrm{g}}$ & $6.35 \pm 0.04^{\mathrm{g}}$ \\
\hline
\end{tabular}

Transverse relaxation time reflects the combination degree of moisture and protein of dumpling wrappers. The weak binding water T22 and the free water T23 in the dumpling wrappers showed a decreasing trend with the storage time prolonged, which indicated that the moisture content of the dumpling wrappers had a tendency to decrease with the increase of storage time. This is mainly because in the storage process, the free water evaporates and loses, and the remaining water is combined with other components to synthesize the water which is not easy to flow. From the various forms of water proportion, the weakly bonded water accounted for more than $90 \%$ of water content. With the storage time increased, the proportion decreased and the ratio of free water increased significantly. The results show that with the extension of storage time, the degree of freedom of water increased continuously, and the compactness of the combination with other components decreased gradually.
Changes of free sulfhydryl (-SH) contents in dumpling wrappers during storage at room temperature

During the preparation of dumpling wrappers, some free sulfhydryl groups combine to form disulfide bonds, thus promoting the formation of gluten network structure. Therefore, the free sulfhydryl content in dumpling wrappers can be used as an important index to characterize the degree of gluten network structure formation (Gujral et al., 2004). As shown in figure 3, the content of free sulfhydryl groups showed a significant upward trend. This indicates that with the extension of storage time, gluten's network structure becomes loose, resulting in the decrease of the elasticity of dumpling wrappers, the weakening of water binding capacity, and the change of water form from weak bound water to free water, which is unfavorable to the eating quality of dumpling wrapper. 


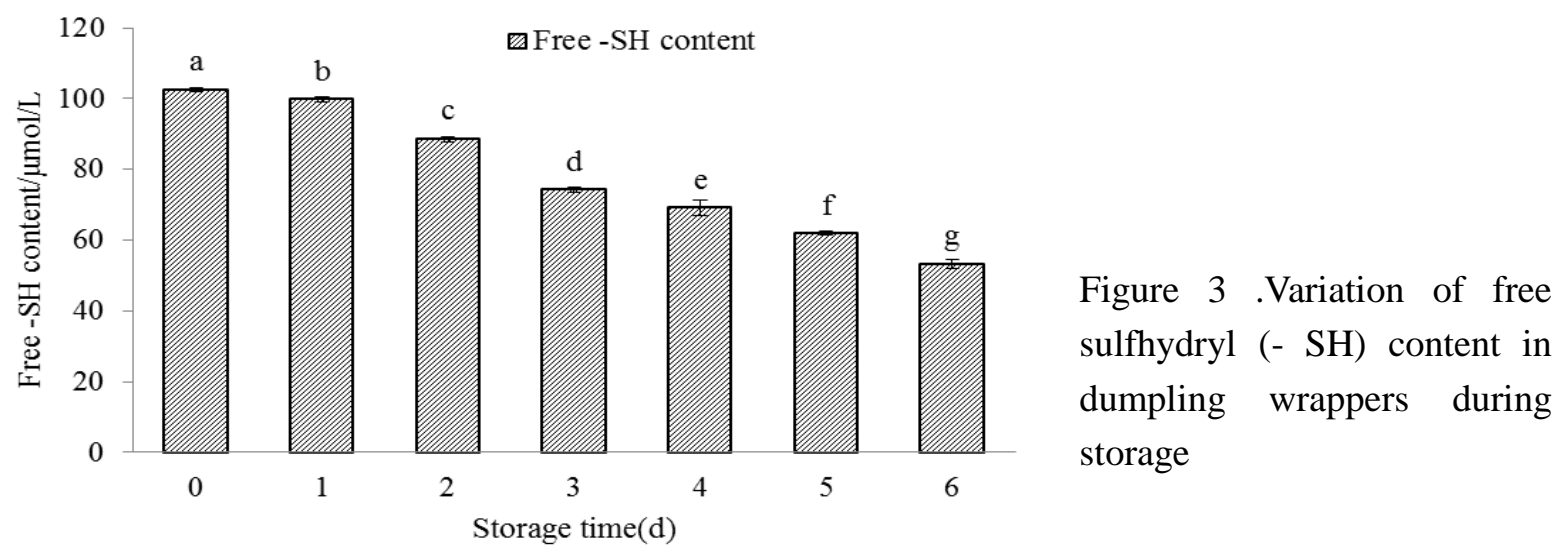

Microbial changes of dumpling wrappers during storage at room temperature

Microbial content is a key index to evaluate the shelf quality of dumpling. Dumpling wrappers in the production are generally not through the sterilization process. Affected by the raw materials and microorganisms, dumpling wrappers contain a certain amount of micro-organisms. From Figure $4 \mathrm{Can}$ be seen, dumpling wrappers microorganisms mainly bacteria and mold. Due to the high water content

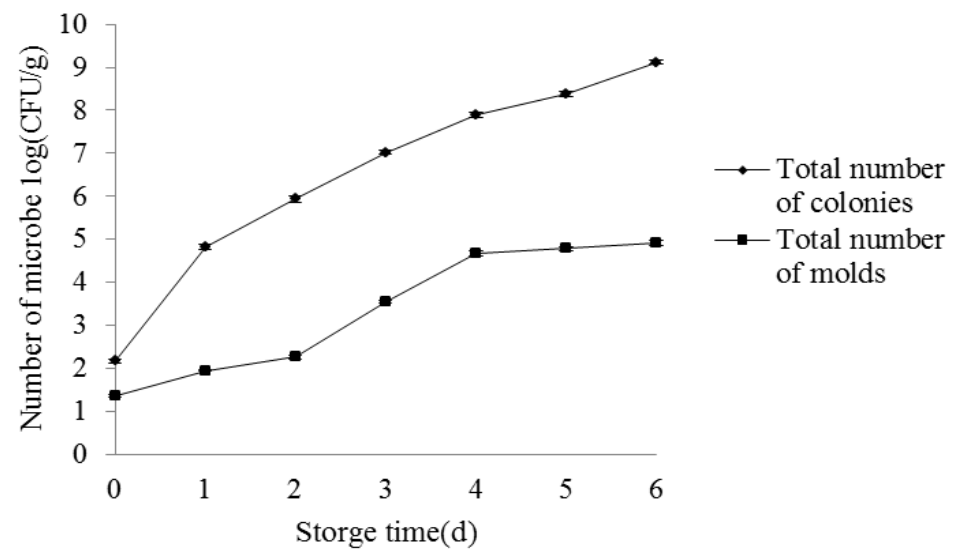

Figure 4 .Microbial changes of dumpling wrappers during storage

Color changes in the dumpling wrappers during storage at room temperature

Browning is another important factor affecting the quality of dumpling wrappers during storage. As shown in Figure 5, with the extension of storage time, dumpling wrapper's $L^{*}$ value decreased gradually, especially in the first to third days the most obvious changes, the initial value of 76.88, third days has been reduced from fourth days to 74.03. Within sixth days of decline is relatively flat. The value of a * increased with the storage time, and the value and rich matrix nutrition of the dumpling wrappers, the microorganism is easily growing and propagating rapidly during room temperature. From Figure 4 can be clearly seen that the total number of colonies and the total number of molds increased significantly with the prolongation of storage time. When stored for sixth days, the total number of bacteria increased to $3.63 \times 10^{8} \mathrm{CFU} / \mathrm{g}$, and the total number of fungi increased to $8.32 \times 10^{4} \mathrm{CFU} / \mathrm{g}$. increased from 0.85 to 2.18 on the 6th day, which increased by nearly 2.5 times. The decrease of $\mathrm{L} *$ value of dumpling wrappers and the increase of a* value were mainly due to the oxidative browning of polyphenol oxidase in the raw material and the refraction and dispersion of dumpling wrappers surface and internal molecules. As the storage time was prolonged, the loosening of the network structure not only leads to a decrease in the light reflectance, but also causes the polyphenol oxidase to react more easily with the substrate (Ong et al., 2010). 


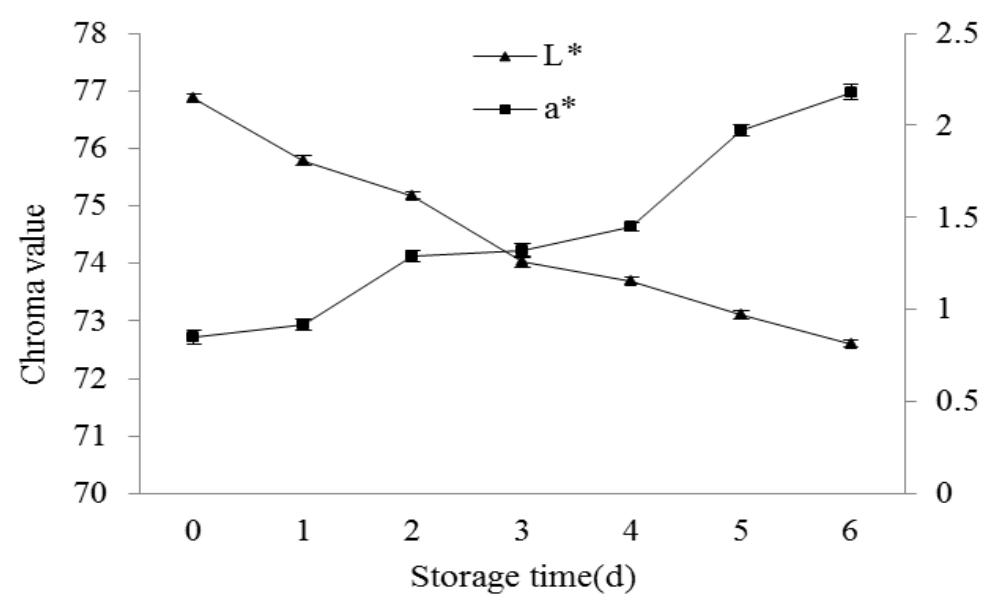

Figure 5 .The color value changes of dumpling wrappers during storage

pH changes in dumpling wrappers during storage at room temperature

As shown in Figure. $6, \mathrm{pH}$ decreased significantly from 6.32 to 5.71 in the first two days of storage, which was mainly caused by fermentation of acid in the process of growth and reproduction of microorganisms in dumpling wrappers. On the third day, the $\mathrm{pH}$ value increased to a certain extent, but the trend of increase was not obvious. It was only 0.02 higher than that in the second day. Then $\mathrm{pH}$ still showed a decreasing trend, but the trend was relatively gentle. The main reason is that the alkaline substances such as amines and ammonia, which are produced by protein decomposition in the later period of storage, neutralize part of the acid (Zhong et al., 2013).

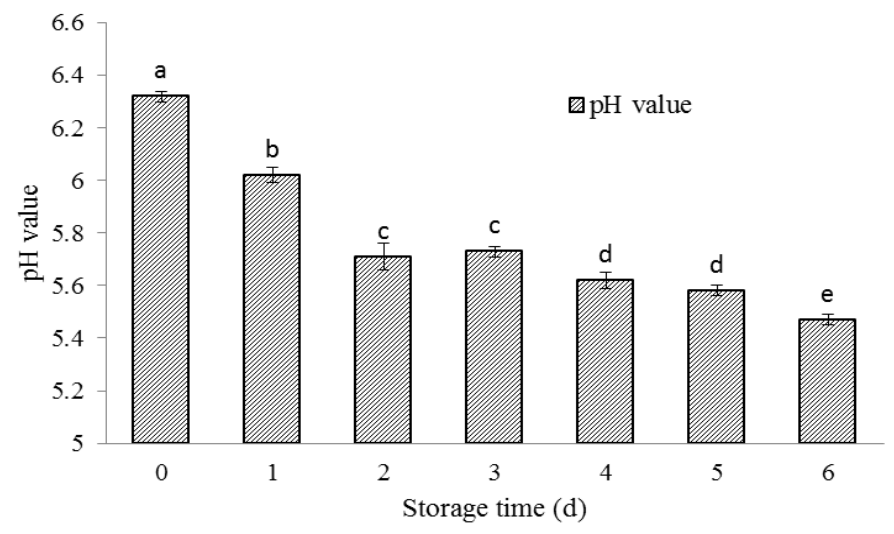

Figure 6 .The change of $\mathrm{pH}$ value of dumpling wrappers during storage

Changes of texture characteristics of dumpling wrappers during storage at room temperature

The change of texture parameters during dumpling wrappers storage is shown in Table 4. Except for hardness, the elasticity and chewiness decreased with the prolongation of storage time. The elastic change was most obvious. Chewing degree did not change significantly in the first two days of storage, and then decreased dramatically. The hardness value increased during the first three 3 days of storage and then decreased. The increase of hardness in the early stage may be related to the water loss. However, with the extension of storage period, the damage of gluten network structure and the transformation from weakly bound water to free water, the hardness began to show a downward trend.

Changes of cooking characteristics of dumpling wrappers during storage at room temperature

With the storage time extension, the optimal cooking time and water absorption rate of two indicators show a decreasing trend (Table 5). This may be because with the propagation of microbes and the destruction of the structure of 
the network, the water is easier to enter the inside of the dumpling wrappers, causing the cooking time to be reduced. But on the other hand, the binding capacity of protein and starch and other substances is weakened, which reduces the water absorption. The loss rate increased with the prolongation of storage time, from $5.96 \%$ to $6.76 \%$ (Ziyi Zheng, 2013).

Table 4 .Changes in the texture of dumpling wrappers during storage

\begin{tabular}{|c|c|c|c|}
\hline \multirow{2}{*}{$\begin{array}{l}\text { Storage time } \\
\text { (d) }\end{array}$} & \multicolumn{3}{|c|}{ Texture parameters } \\
\hline & Hardness (N) & Elasticity & Chewiness \\
\hline 0 & $75.86 \pm 2.91^{\mathrm{b}}$ & $0.643 \pm 0.01^{\mathrm{f}}$ & $54.68 \pm 0.39^{\mathrm{e}}$ \\
\hline 1 & $81.42 \pm 0.91^{\mathrm{de}}$ & $0.627 \pm 0.002^{\mathrm{e}}$ & $54.61 \pm 0.38^{\mathrm{e}}$ \\
\hline 2 & $83.58 \pm 1.05^{\mathrm{e}}$ & $0.624 \pm 0.001^{\mathrm{e}}$ & $53.74 \pm 0.32^{\mathrm{e}}$ \\
\hline 3 & $87.13 \pm 2.51^{\mathrm{f}}$ & $0.607 \pm 0.004^{\mathrm{d}}$ & $47.82 \pm 1.18^{\mathrm{d}}$ \\
\hline 4 & $79.46 \pm 2.24^{\mathrm{cd}}$ & $0.561 \pm 0.003^{\mathrm{c}}$ & $40.16 \pm 0.36^{c}$ \\
\hline 5 & $76.29 \pm 1.01^{\mathrm{bc}}$ & $0.516 \pm 0.004^{b}$ & $38.69 \pm 0.13^{b}$ \\
\hline 6 & $72.31 \pm 1.18^{\mathrm{a}}$ & $0.484 \pm 0.006^{\mathrm{a}}$ & $37.24 \pm 0.41^{\mathrm{a}}$ \\
\hline
\end{tabular}

Table 5 .Changes in cooking characteristics of dumpling wrappers during storage

\begin{tabular}{|l|l|l|l|}
\hline Storage time $(\mathrm{d})$ & Optimum cooking time $(\mathrm{s})$ & Absorption rate $(\%)$ & Cooking loss rate $(\%)$ \\
\hline 0 & 330 & $76.77 \pm 0.46^{\mathrm{g}}$ & $5.96 \pm 0.26^{\mathrm{d}}$ \\
\hline 1 & 320 & $75.66 \pm 0.38^{\mathrm{f}}$ & $5.98 \pm 0.36^{\mathrm{d}}$ \\
\hline 2 & 300 & $74.23 \pm 0.45^{\mathrm{e}}$ & $6.09 \pm 0.36^{\mathrm{c}}$ \\
\hline 3 & 265 & $72.17 \pm 0.57^{\mathrm{d}}$ & $6.18 \pm 0.09^{\mathrm{c}}$ \\
\hline 4 & 235 & $70.07 \pm 0.55^{\mathrm{c}}$ & $6.47 \pm 0.08^{\mathrm{b}}$ \\
\hline 5 & 200 & $66.85 \pm 0.26^{\mathrm{b}}$ & $6.55 \pm 0.04^{\mathrm{b}}$ \\
\hline 6 & 175 & $63.54 \pm 0.30^{\mathrm{a}}$ & $6.76 \pm 0.04^{\mathrm{a}}$ \\
\hline
\end{tabular}

Correlation analysis of the change of main quality index

Table 6 shows the correlation analysis between physicochemical indexes and microbial indexes of dumplings wrappers and sensory quality indexes such as color, texture, etc. The results showed that water content, water morphology, free sulfhydryl group and total bacterial count were significantly correlated with sensory index of dumpling wrappers $(\mathrm{P}<0.01)$ such as color, texture and cooking characteristic

Table 6 .The correlation analysis of the indicators of dumpling wrappers during storage

\begin{tabular}{|l|l|l|l|l|l|l|}
\hline Indicator & $\begin{array}{l}\text { Moisture } \\
\text { content }\end{array}$ & $\mathrm{P}_{22}$ & $\mathrm{P}_{23}$ & $\begin{array}{l}\text { free - SH } \\
\text { content }\end{array}$ & $\begin{array}{l}\text { Total no of } \\
\text { colonies }\end{array}$ & $\begin{array}{l}\text { Total no of } \\
\text { molds }\end{array}$ \\
\hline $\mathrm{L}^{*}$ & $0.990^{* *}$ & $0.993^{* *}$ & $-0.993^{* *}$ & $-0.969^{* *}$ & $-0.989^{* *}$ & $-0.979^{* *}$ \\
\hline $\mathrm{a}^{*}$ & $-0.918^{* *}$ & $-0.962^{* *}$ & $0.962^{* *}$ & $0.967 * *$ & $0.896^{* *}$ & $0.898^{* *}$ \\
\hline $\mathrm{pH}$ & $0.975^{* *}$ & $0.933^{* *}$ & $-0.933^{* *}$ & $-0.900^{* *}$ & $-0.970^{* *}$ & $-0.915^{* *}$ \\
\hline Hardness & 0.181 & 0.344 & -0.344 & -0.440 & -0.155 & -0.246 \\
\hline Elasticity & $0.878^{* *}$ & $0.947 * *$ & $-0.947 * *$ & $-0.971 * *$ & $-0.866^{* *}$ & $-0.886^{* *}$ \\
\hline Chewiness & $0.907 * *$ & $0.955^{* *}$ & $-0.955^{* *}$ & $-0.968^{* *}$ & $-0.906^{* *}$ & $-0.959^{* *}$ \\
\hline $\begin{array}{l}\text { Optimum } \\
\text { cooking time }\end{array}$ & $0.940^{* *}$ & $0.987 * *$ & $-0.987 * *$ & $-0.988^{* *}$ & $-0.931^{* *}$ & $-0.956^{* *}$ \\
\hline Absorption rate & $0.916^{* *}$ & $0.974 * *$ & $-0.974 * *$ & $-0.976^{* *}$ & $-0.902^{* * *}$ & $-0.918^{* *}$ \\
\hline $\begin{array}{l}\text { Cooking loss } \\
\text { rate }\end{array}$ & $-0.909^{* *}$ & $-0.967 * *$ & $0.967 * *$ & $0.978^{* *}$ & $0.898^{* *}$ & $0.932^{* *}$ \\
\hline
\end{tabular}

Note: $* *$ is significantly correlated at 0.01 level (both sides). 


\section{CONCLUSION}

The color of dumpling wrappers became darker and the value of $\mathrm{L}^{*}$ was decreased and the value of a $*$ increased. The texture of dumpling wrappers was changed obviously. The hardness, chewiness and elasticity of the dumpling wrappers decreased gradually and the viscosity increased. The optimum cooking time was shortened, the absorption rate decreased and the cooking loss rate increased. With the prolongation of storage time, the content of free sulfhydryl in the dumpling wrappers increased significantly. With the prolongation of storage time, the original structure of fresh dumpling wrappers was destroyed, and the moisture distribution was uneven and migrated to the surface. According to the correlation analysis of the main quality indexes, it can be seen that the moisture content, water form, free sulfhydryl group and total number of colonies showed significant correlation with the sensory indexes such as color, texture and cooking characteristics except the hardness index of dumpling wrappers ( $\mathrm{P}<0.01)$. In conclusion, the deterioration of the quality of the dumpling wrappers during storage is the result of the network structure of water, gluten and the common effect of the growth and reproduction of microbes. Therefore, controlling the proper moisture content, enhancing the gluten network structure of the dumpling wrappers, reducing and inhibiting the growth and reproduction of microorganisms are important problems to be solved to maintain the good quality of dumpling wrappers.

\section{ACKNOWLEDGEMENTS}

This work was financially supported by Tianjin science and technology plan projects (16YFZCNC00680) and National Science and Technology Pillar (2015BAD16B05)

\section{REFERENCES}

1. Addo, K., Pomeranz, Y., Huang, M. L., Rubenthaler, G. L., \& Jeffers, H. C. (1991). Steamed bread. ii. role of protein content and strength. Cereal Chemistry, 68, 39-42.

2. Baik, B. K., Czuchajowska, Z., \& Pomeranz, Y. (1994). An sds-fy test to evaluate quality of wheat for oriental noodles. Journal of Cereal Science, 20(20), 191-201.

3. Clark, C. J., Macfall, J. S., \& Bieleski, R. L. (1998). Amelioration of watercore in Fuji apple viewed by two- and three-dimensional nuclear magnetic resonance imaging. Acta Horticulturae, (464), 91-96.

4. Gujral, H. S., \& Rosell, C. M. (2004). Functionality of rice flour modified with a microbial transglutaminase. Journal of Cereal Science, 39(2), 225-230.

5. Zhang H. (2013). Study on the Relationship between Gluten Protein Propertties and Dumpling Wrapper Qualities. Unpublished doctoral dissertation. Zhengzhou: Henan Polytechnic University.

6. Huang, S., Quail, K., \& Moss, R. (1998). The optimization of a laboratory processing procedure for southern-style chinese steamed bread. International Journal of Food Science \& Technology, 33(4), 345-357.

7. Lan, J., Fu, B. X., Assefaw, E., Wang, L. K., Li, H., \& Dai, C. J., et al. (2010). Relationship between flour physico-chemical properties and dumpling sheet quality. Scientia Agricultura Sinica, 43(6), 1204-1211.

8. Li, T., Wang, X., Ma, S., Wang, C., \& Li, J. (2014). Effects of storage conditions on the moisture state and quality of fresh wet noodles. Cereal \& Feed Industry, 07:31-35.

9. Li, W., Dobraszezyk, B. J., \& Schofield, J. D. (2003). Stress relaxation behavior of wheat dough, gluten, and gluten protein fractions. Cereal Chemistry, 80(3), 333-338.

10. Li, Z. (2008). Application of texture anaylzer to determination of noodle quality. Academic Periodical of Farm Products Processing, 142(7):188-192.

11. Liu, C. Y., Guo, Y., Chen, N., \& Liang, J. F. (2012). Effect of moisture content on mechanical properties of freezing dumpling sheet. Food Science \& Technology, 37(9):134-139.

12. Liu, R., Wu, L., Zhang, Y., Zhang, H., Zhang, B., \& Huang, B., et al. (2015). Water state and 
distribution in noodle dough using low-field nuclear magnetic resonance and differential scanning calorimetric.Nongye Gongcheng Xuebao/transactions of the Chinese Society of Agricultural Engineering, 31(9), 288-294.

13. McEntyre, E., Ruan, R., \& Fulcher, R. G. (1999). Comparison of water absorption patterns in two barley cultivars, using magnetic resonance imaging. Cereal Chemistry, 75(6), 792-795.

14. Ong, Y. L., Ross, A. S., \& Engle, D. A. (2010). Glutenin macropolymer in salted and alkaline noodle doughs. Cereal Chemistry, 87(1), 79-85.

15. Pitombo, R. N. M., \& Lima, G. A. M. R. (2003). Nuclear magnetic resonance and water activity in measuring the water mobility in pintado ( pseudoplatystoma corruscans ) fish. Journal of Food Engineering, 58(1), 59-66.

16. Standards Association of China. (1993). Wheat flour for dumpling. LS/T 3203-1993. Beijing: Standard Press

17. Standards Association of China. (2010). Method for determination of starch in foods . GB 5009.9-1985. Beijing: Standard Press

18. Standards Association of China. (2010). National food safety standard: Determination of moisture in food. GB 5009.3-2010. Beijing: Standard Press

19. Standards Association of China. (2010). National food safety standard: Determination of ash in foods. GB 5009.4-2010. Beijing: Standard Press

20. Standards Association of China. (2010). National food safety standard: Determination of protein in foodstuffs. GB 5009.5-2010. Beijing: Standard Press

21. Standards Association of China. (2010). National food safety standard: Food microbiological examination: Aerobic plate count. GB/T 4789.2-2010. Beijing: Standard Press

22. Standards Association of China. (2010). National food safety standard: Food microbiological examination: Enumeration of moulds and yeasts. GB/T 4789.15-2010. Beijing: Standard Press

23. Standards Association of China. (2010). Wheat and wheat flour-Gluten content-Part 1: Determination of wet gluten by manual method. GB/T 5506.1-2008. Beijing: Standard Press

24. Standards Association of China. (2010). Wheat flour-Physical characteristics of doughs Determination of water absorption and rheological properties using a farinograph . GB/T 14614-2006. Beijing: Standard Press

25. Wang, J., Zhao, M., Yang, X., \& Jiang, Y. (2006). Improvement on functional properties of wheat gluten by enzymatic hydrolysis and ultrafiltration. Journal of Cereal Science, 44(1), 93-100.

26. Wang, X. M., Chen, J., Ying-Guo, L. V., \& Liu, Z. L. (2013). Research progress of preservation technology for fresh noodles. Cereals \& Oils, 26(2):12-15

27. Wrigley,C.W., Lookhart,G.L. (1997). Wheat protein as a quality determinant. Proceedings of the International Wheat Quality Conference, 18-22 May 1997(51-59) Manhattan, Kansas.

28. Xue-Hong, L. I., Zhong-Yu, H. U., Yong, L. U., Jing, X. Y., \& Liu, Y. Q. (2014). Effect of the time of frozen on secondary structure of glutenin and gliadin and textural properties of dough. Science \& Technology of Food Industry, 35(1), 83-82.

29. Xue-Qin, L. I., Jing-Jing, G. E., Xie, Q., \& Wang, H. (2012). Relationship between sensory quality and texture quality of dumpling wrapper. J. of Henan University of Technology, 33(4):1-4.

30. Ying-Guo, L., Guo, Y., Yun-Dong, M. U., Long, L. L., \& Zhu, Z. G. (2013). Correlation and path analysis between physicochemical indicators of wheat flour and textural quality of frozen dumpling wrapper. Journal of Henan University of Technology, 24(3):12-16.

31. Zhang, S. B., Qi-Yu, L. U., \& Yan-Hong, L. V. (2005). The effect of lipid on noodle quality. Science \& Technology of Cereals Oils \& Foods, 13(1):12-15.

32. Zheng Z. (2013). Study on quality change of frozen noodles during storage. Unpublished doctoral dissertation. Zhengzhou: Henan Polytechnic University

33. Zhong, S. Y., Liu, S. C., Qin, X. M., Wang, W. M., Lin, H. J., \& Chen, S. H. (2013). Effect of protein decomposition on the quality of vacuum-packed tilapia during low temperature storage. Food Science \& Technology, 38(6):141-146 